\begin{tabular}{|c|c|c|}
\hline $\begin{array}{l}\text { PKS } \\
\text { PUBLIC } \\
\text { KNDOLEDGE } \\
\text { PROJECT }\end{array}$ & $\begin{array}{c}\text { REVISTA DE GEOGRAFIA } \\
\text { (RECIFE) } \\
\text { http://www.rvista.ufpe.br/revistageografia }\end{array}$ & $\begin{array}{l}\text { OJS } \\
\text { OPPN } \\
\text { JOYNAL } \\
\text { SYSSTEM }\end{array}$ \\
\hline
\end{tabular}

\title{
A RETERRITORIALIZAÇÃO PESQUEIRA NO ESTADO DO PARÁ: REPRODUÇÃO CONTRADITÓRIA DAS RELAÇÕES CAPITALISTAS
}

\author{
Daniel Sombra ${ }^{1}$, Giovane da Silva Mota $^{2}$, Alegria dos Santos Leite ${ }^{3}$, Carlos Jorge \\ Nogueira de Castro ${ }^{4}$
}

\begin{abstract}
${ }^{1}$ Professor do Departamento de Filosofia e Ciências Sociais da Universidade do Estado do Pará (DFCS-UEPA). E-mail: dsombra@ufpa.br

${ }^{2}$ Professor da Faculdade de Geografia e Cartografia da Universidade Federal do Pará (FGC-UFPA). E-mail: giovanemota@hotmail.com

${ }^{3}$ Doutoranda em Desenvolvimento Econômico, Território e Meio Ambiente pelo Programa de Pós-Graduação em Economia da Universidade Federal do Pará (PPGE-UFPA). E-mail: alegria1717@gmail.com

${ }^{4}$ Professor do Departamento de Filosofia e Ciências Sociais da Universidade do Estado do Pará (DFCS-UEPA). Mestre em Geografia pelo Programa de Pós-Graduação em Geografia da Universidade Federal do Pará (PPGEOUFPA). E-mail: carlosjorge319@gmail.com
\end{abstract}

Artigo recebido em 11/09/2016 e aceito em 29/01/2018

\section{RESUMO}

O ordenamento territorial pós-1960 na Amazônia erige uma nova organização espacial, com as empresas capitalistas como agentes hegemônicos, com destaque para a indústria pesqueira no Nordeste Paraense. A apropriação do território pelos novos agentes hegemônicos desterritorializou os agentes que realizavam uma apropriação comum do território: os pescadores artesanais. Essa desterritorialização implicou numa reterritorialização (modo de reprodução da pesca artesanal encontrado a partir da inserção da pesca industrial: uma territorialização precária) que se deu através: $a$ ) da especialização em pescar espécies que não interessam aos grandes atores; ou $b$ ) da conversão em força de trabalho para os novos agentes sociais. A natureza a ser (re)territorializada é, porém, tecnificada, no sentido em que já não pode ser apropriada ou concebida conforme a técnica e as práticas anteriores. Daí deriva a hipótese central de que a produção da nova organização espacial da pesca no Nordeste Paraense se dá simultaneamente com a territorialização "enquanto recurso" para alguns e reterritorialização "enquanto abrigo" para outros. Sob estes moldes, a reterritorialização da pesca artesanal é um momento da reprodução ampliada do capital, sob a forma de acumulação primitiva (acumulação por espoliação).

Palavras-chave: Territorialidades, Gestão do Território, Usos do território.

\section{THE FISHMAN'S RETERRITORIALIZATION IN THE STATE OF PARÁ: CONTRADITORY REPRODUCTION OF CAPITALIST RELATIONS}

\begin{abstract}
The post-1960 land use in the Amazon erects a new spatial organization with capitalist enterprises as hegemonic agents, highlighting in Northeast Para the fishing industry. The appropriation of the territory by the new hegemonic agents deterritorialized agents who were holding a joint ownership of the territory: the artisanal fishermen. This dispossession resulted in reterritorialization (artisanal fisheries way of reproduction found from the insertion of industrial fishing: a precarious territorialization) that occurred through: $a$ ) specialization in fish species that do not interest the major players; or $b$ ) conversion of the workforce to the new social agents. The nature to be (re) territorialized is, however, technified, in the sense that it can no longer be appropriate or designed according to technical and past practice. Hence the central hypothesis that production of the new spatial
\end{abstract}


organization of fishing in the Northeast Amazon takes place simultaneously with the territorial "as a resource" for some and Repossession "as a shelter" to others. Under these templates, the repossession of artisanal fishing is a time of expanded reproduction of capital, in the form of primitive accumulation (accumulation by dispossession).

Keywords: Territorialities, Land Management, uses territory.

\section{INTRODUÇÃO}

O território é o espaço dinamizado a partir de relações de poder - relações de controle do uso dos recursos ou dos movimentos no espaço. A forma central da territorialização (da apropriação dos recursos e do ditame dos ritmos, comportamentos e acessos ao espaço produzido), varia de acordo com a estrutura social da produção. Em uma sociedade onde a produção se dá a partir da desigualdade, onde uma classe tenha se apropriado do espaço bem comum e produzido por todos, tem-se uma apropriação desigual (MOREIRA, 1982), uma territorialização privada, no sentido em que priva os produtores ao acesso da própria obra produzida (que está sempre em produção; totalidade em totalização).

Este é o caso das sociedades nas formações espaciais capitalistas, nas quais ocorre uma apropriação por alguns, que se convertem por força de seus meios impositivos nos proprietários dos recursos do território, em detrimento dos demais que ficam com sua própria energia corpórea (RAFFESTIN, 1993) como único recurso, alienada dos meios de produção (MOREIRA, 1982), portanto, desterritorializada (HAESBAERT, 2009). Na formação capitalista a produção do espaço é socializada, seguida de uma apropriação privada do território, face complementar da socialização capitalista (SANTOS, 1994).

Cada formação espacial, contudo, é uma totalidade onde a territorialização hegemônica convive dialeticamente com outras formas de territorialização, por vezes destruindo-as, mantendo-as, ou reproduzindo-as, conforme os acordos e as lutas entre as classes. "Como uma formação social é um complexo organizado de vários modos de produção, o excedente gerado nesta formação não é homogêneo. Existe uma adição de excedentes com origens diferentes" (AMIN, 1976, p.13). No caso das sociedades nas formações capitalistas, percebese que a expansão do modo de produção capitalista implica na reprodução de modos de produção dependentes, hegemonizados pelo capital (VERGOPOULOS, 1977).

No processo-mundo (mundo em realização a partir da hegemonia da reprodução capitalista), a Amazônia foi configurada como uma formação espacial periférica. Sua função tem sido a de fronteira: fonte regular de acumulação primitiva e mais-valia absoluta (LOBATO; SOARES, 2015). Os arranjos espaciais com os quais foi apropriada lhe 
direcionam o papel de região periférica, ou seja polarizada a partir dos vetores centrais da formação espacial brasileira. A partir dos anos 1960 há uma mudança na forma de regulação espacial nesta região (IANNI, 1979). A aliança de classes entre os proprietários dos meios de produção locais e externos é modificada no sentido de permitir uma maior apropriação do trabalho produzido na Amazônia. As elites tradicionais (os "coronéis") passam a conviver com os novos atores hegemônicos: as empresas capitalistas (OLIVEIRA, 1987). A partir daí se modifica qualitativamente o processo de integração do espaço amazônico ao sistema de formações espaciais com produção capitalista propriamente dita, no qual se efetuará a sujeição da renda territorial ao capital - agora preferencialmente renda em dinheiro (GONÇALVES, 2001). A Amazônia se converte efetivamente em fronteira para o capital acumulado (excesso de liquidez) e o trabalho excedente (desemprego estrutural, êxodo rural) das áreas mais capitalizadas.

Neste processo de ajuste espacial para ampliar a acumulação, várias frentes foram implementadas em direção à Amazônia, as quais podemos grosso modo dividir em duas (MARTINS, 2009): $a$ ) a frente de expansão (a frente de instalação do trabalho); e, $b$ ) a frente pioneira (a frente de implantação do capital). A primeira agrega à região uma massa de trabalhadores (migrantes) que se apropria dos recursos dos indígenas e dos trabalhos dos posseiros (ANDRADE, 1970), e produz um novo espaço geográfico, que é, contudo, territorializado pelo capital posteriormente na segunda frente (OLIVEIRA, 1997). O Estado é o cimento desse novo compromisso entre as classes - possuidores e não possuidores - bem como da particular aliança entre novas e velhas elites, em um processo de conversão dos “coronéis" em capitalistas (e, simultaneamente, dos capitalistas em "coronéis") (OLIVEIRA, 1987).

O Estado, sob a forma de políticas públicas setorizadas nos planos específicos, viabilizou as condições efetivas para esta nova aliança, na qual os empresários capitalistas se tornaram proprietários das terras e das águas. A Superintendência de Desenvolvimento da Amazônia (SUDAM) foi um dos órgãos chaves na apropriação do território pelas empresas capitalistas, principalmente as agropecuárias e mineralógicas (LOUREIRO, 2004). Mas especificamente no Nordeste Paraense, a empresa capitalista hegemônica é a empresa pesqueira, regulada pela reprodução ampliada do capital e expressa pelo aprimoramento da técnica (PENNER, 1984). 


\section{TERRITÓRIO E PESCA NA AMAZÔNIA}

$\mathrm{Na}$ Amazônia, os pescadores artesanais costumam ter o controle do processo de trabalho, embora não possuam o mesmo controle sobre o produto de seu trabalho (LOUREIRO, 1987). Historicamente não possuem as propriedades fundiárias sobre as quais atuam, tão pouco sobre as águas onde efetuam suas atividades. A herança ameríndia é verificada nas técnicas e nos instrumentos de trabalho utilizados ainda hoje. Mas objetivo histórico da pesca na Amazônia tem sido abastecer as grandes cidades e vilas locais, e para tal, no período colonial, foram criados os chamados Pesqueiros Reais. Neste ordenamento, os pescadores não eram proprietários do material de trabalho, mas o eram dos meios de produção, uma vez que eles mesmos os confeccionavam, fazendo, para tal, uso de métodos ameríndios, com alguns aperfeiçoamentos portugueses (FURTADO, 1981). A herança dos pesqueiros se dá na forma de apropriação erigida a partir da República, com grandes companhias de pesca arregimentando pescadores despossuídos em regime de parceria. Modelo que ainda é verificado nos dias correntes (LOUREIRO, 1987).

A partir da segunda metade do século $\mathrm{XX}$, as sedes municipais dos principais municípios da zona costeira paraense, no Nordeste Paraense e no Marajó passam a receber um incremento do seu número de pescadores, em virtude do crescente êxodo rural (LOUREIRO, 1987). É neste momento, pela primeira vez na história da Amazônia, que se engendra a figura do pescador enquanto pescador, pois até então, o que havia eram produtores polivalentes, no sentido em que os sujeitos plantavam, pescavam e caçavam, fazendo de suas habitações mosaicos produtivos (LOUREIRO, 1985).

No Nordeste Paraense a pressão fundiária da pecuária na zona bragantina leva um grande contingente de trabalho para as regiões de solos aluviais, onde são estabelecidos pelo Instituto Nacional da Colonização e Reforma Agrária (INCRA) uma grande quantidade de minifúndios. Mantidos os métodos tradicionais, em poucas gerações o solo só é capaz de produzir mandioca. Este fenômeno aliado a outras formas de expulsão do campo resulta na migração para as cidades. No Marajó, por outro lado, configurou-se mais claramente a absorção de terras da pequena agricultura pela pecuária bubalina. Historicamente naquele arquipélago as fazendas não têm cercas, e os limites são demarcados pelo próprio gado ferrado. A expansão da pecuária no regime pós-1960 levou ao êxodo dos agricultores para as sedes municipais (LOUREIRO, 1987).

O êxodo rural no Pará, portanto, não tem sido produto de uma modernização no campo, mas fruto da valorização da terra, açambarcada por agentes portadores de capital, ou 
regularizado a partir do Estado em moldes improdutivos para a pequena agricultura. Essa é a origem dos pescadores despossuídos que vão trabalhar na pesca artesanal em cidades como a Vigia (LOUREIRO, 1985), ou Soure (LOUREIRO, 1987), as duas maiores produtoras do pescado consumido em Belém nos anos 1960. Nessas cidades, os pescadores estão atados a relações monetizadas para satisfazer suas necessidades básicas, embora não trabalhem em um regime assalariado.

A maioria absoluta dos pescadores trabalham em regime de parceria, no qual eles entram apenas com a mão-de-obra, enquanto que outra parte entra com os instrumentos de trabalho (canoa, rede, motor, gelo etc.). A remuneração se dá com uma parte do produto pescado (FURTADO, 1987). Entrementes, a partir do novo regime de regulação pós-1960, não somente se acentuou dentro da pesca artesanal as disparidades entre os proprietários e os parceiros (pescadores despossuídos) através do crédito bancário, disponível apenas aos primeiros, como se deu margem a uma atividade especificamente capitalista, com regime assalariado e alto incremento de capital atuando no Nordeste Paraense e no Marajó: a pesca industrial (PENNER, 1984).

Segundo Oliveira (1996), de 1964 a 1985 a preocupação constante de ocupação da Amazônia materializou-se na criação de incentivos à penetração do capital nacional e internacional no mercado de terras, com vantagens fiscais para a criação de grandes projetos agropecuários, atraindo trabalhadores rurais para programas de colonização dirigida, abrindo estradas e consolidando a infraestrutura de transportes, comunicações e energia elétrica, principalmente para o insumo energético de grandes indústrias do setor mineral. Conforme Monteiro e Coelho (2004), estes projetos configuravam uma estratégia de controle territorial e econômico da Amazônia por parte dos governos militares, que neste ponto pareciam dar plena continuidade à política de expansão rumo ao Oeste proclamada pelo governo Vargas, ainda nos anos 1930 (VELHO, 1976).

Na Amazônia Oriental, porém, esta estratégia de controle territorial a partir da parceria com empresas capitalistas significou uma alteração da estratégia executada pelo Estado desde a República Velha com relação ao setor pesqueiro. Conforme Resende (2014), o Estado Brasileiro, através da Marinha, buscou a institucionalização da pesca artesanal ainda nos anos 1910-1920 através das colônias de pescadores objetivando o açambarcamento do conhecimento extraído do notório saber dos pescadores, além de convertê-los, de algum modo, em colaboradores não oficiais das Forças Armadas. A estratégia se materializou na 
implantação das colônias, e, com elas, a instalação de escolas e postos de saúdes em localidades longínquas espraiadas ao largo do litoral brasileiro (RESENDE, 2014).

O final dos anos 1960 marca uma ruptura desta política, pois com os incentivos fiscais da SUDAM se instalam no Pará duas grandes empresas internacionais, com sede em Belém e área de atuação na Baía do Marajó, com base de pesca na Vigia (TORRES, 1999). Em 1970 se dá a expansão das águas territoriais para exploração econômica exclusiva de 12 para 200 milhas náuticas (de 22,22 km para 370,4 km) (KLAUTAU, 2012). E segue a isso o aumento do número de empresas: de 02 a 15 (PENNER, 1984) e o aumento da frota de então para 50 embarcações camaroneiras e 20 piramutabeiros (SEPAQ, 2014). Em 1972, objetivando consolidar a exclusividade econômica e o reconhecimento internacional das 200 milhas, o governo brasileiro permite que barcos estrangeiros operem no mar territorial, amparado por licenças especiais (PENNER, 1984), ao passo que em 1976 se atinge o pico do número de embarcações internacionais operando no Estuário do Amazonas: 645 embarcações (SEPAQ, 2014).

O final dos anos 1970 marca a primeira crise ambiental provocada pela pesca industrial. Em 1977, a produção barco/ano de camarão cai de 55 toneladas para 29 toneladas (SEPAQ, 2014). Entretanto, a produção global de piramutaba atingia 30 mil toneladas, maior safra já registrada (KLAUTAU, 2012). Em 1983, a Superintendência para o Desenvolvimento da Pesca (SUDEPE) institui a Portaria $n^{\circ} 9$ de 9 de março daquele ano, visando reduzir o conflito entre pescadores industriais e artesanais proibindo a pesca industrial (pesca de arrasto) de atuar em latitude e longitude inferiores a $00^{\circ} 05^{\prime} 00^{\prime}$ ' $\mathrm{N}$ e $48^{\circ} 00^{\prime} 00^{\prime}$ ' $\mathrm{W}$, respectivamente (KLAUTAU, 2012), conforme se visualiza na figura 1. 
Figura 1: Mapa das mudanças nos limites da Zona Exclusiva para a Pesca Artesanal no Pará

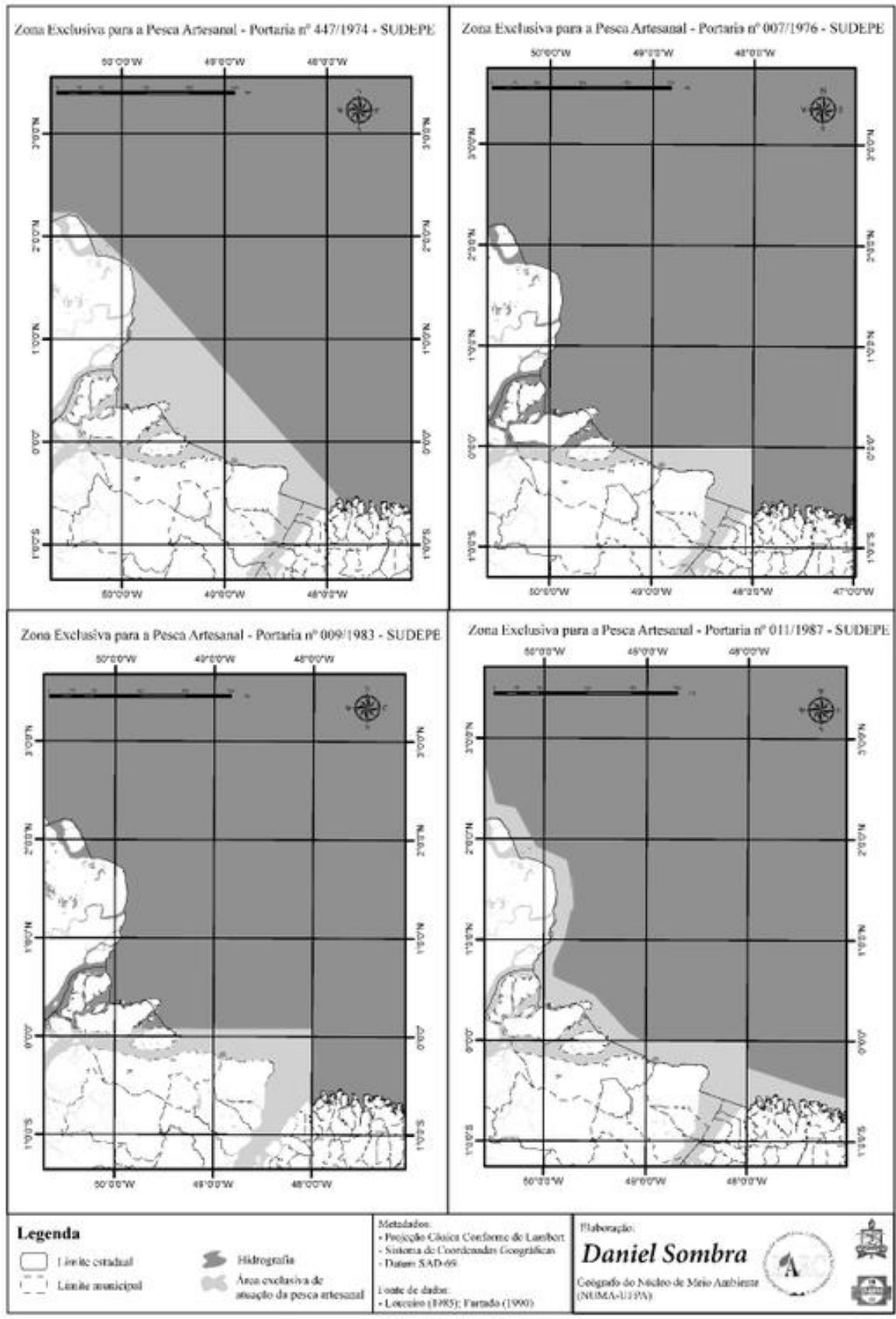

Fonte: LOUREIRO (1985); FURTADO (1987); KLAUTAU (2012); IBAMA (2004); adaptado por SOMBRA (2017)

No final da década de 1980 e início da década de 1990 a preocupação maior, entretanto, no âmbito do governo federal, era a solução de problemas do ambiente macroeconômico, no qual a instabilidade era marcada pelo descontrole da inflação, estagnação da economia e crise de financiamento do setor público. Ao mesmo tempo em que era necessário aos olhos dos estadistas um programa de estabilização, tornava-se prioritário o estabelecimento reformas com o intuito de rever as formas de atuação e financiamento do Estado. A partir de então, 
várias são as reformas ocorridas: políticas destinadas à liberalização do comercio exterior e dos fluxos, e das aplicações do capital estrangeiro; reformas destinadas à estabilidade de preços; à privatização de empresas, à desregulamentação dos mercados de bens e serviços e a eliminação de distorções nos sistemas tributários e financeiros, ou seja, a solução de vários problemas nacionais, muitas vezes, em caráter de curto prazo. Não constam, portanto, grandes mudanças nas políticas voltadas à pesca, seja industrial ou artesanal, durante os anos 1990.

Com o advento do Governo Lula, no início dos anos 2000, o caráter socioeconômico conservador das políticas públicas perdeu espaço para uma nova política de enfrentamento das desigualdades regionais (COSTA, INHETVIN, 2005). De acordo com Soares et al (2016), os anos 2000 do Governo Lula e Dilma marcam um retorno à expansão da fronteira e do controle territorial por parte do Estado Brasileiro, com uma característica nova: um planejamento macroescalar com trabalho em escalas menores (mesorregiões e microrregiões), a fim de dinamizá-las de acordo com suas peculiaridades, do ponto de vista econômico, em um grande modelo de "conciliação de classes". Para Córdoba et al (2018), este é também o momento em que outro olhar de território é incorporado às políticas públicas, onde os programas territoriais tentaram conciliar modelos antagônicos de desenvolvimento rural, particularmente no caso da expansão da dendeicultura no Pará.

Para Nahum e Malcher (2012), com essas políticas territoriais, o conteúdo diverso dos territórios é anulado em torno de uma única agenda, mormente os territórios da cidadania do então Ministério do Desenvolvimento Agrário (MDA) para a implantação de políticas de subsídios e fomento à agricultura familiar, e os territórios da pesca - que coincidem com os primeiros - adotados pelo então Ministério da Pesca e da Aquicultura (MPA). Um dos programas que deve ser mencionados é o Programa Avança Brasil do Governo Federal (20002007) que marca esse novo ciclo através de investimentos em energia e infraestrutura (COSTA, INHETVIN, 2005), cujas metas foram posteriormente incorporadas pelo Programa de Aceleração do Crescimento (PAC).

Em meio a este contexto de retorno às políticas de planejamento em longo prazo, no que tange especificamente à pesca na Amazônia Oriental, em 2004, o Instituto Brasileiro do Meio Ambiente e dos Recursos Naturais Renováveis (IBAMA), através da Instrução Normativa $\mathrm{n}^{\circ} 6$ de 07, mantém a regulamentação da área de pesca proibida para a pesca industrial (pesca de arrasto) da Portaria $\mathrm{n}^{\circ} 9$ da SUDEPE, e institui o "Período do Defeso" entre 15/09 e 30/11 para a reprodução de alevinos no Estuário Amazônico (KLAUTAU, 2012). Segue a isto, em 2007, a institucionalização do seguro defeso e do direito de 
aposentadoria aos pescadores garantidos pelo MPA. Em 2013, o estado do Pará, após vinte anos, retoma o posto de maior produtor nacional de pescado, ultrapassando Santa Catarina, com uma produção de 728.393,80 toneladas de pescado, sendo que 670.961 da pesca artesanal $(92,1 \%), 41.250$ da pesca industrial $(5,7 \%) 16.182$ da piscicultura (2,2\%) (SEPAQ, 2014). Em 2014, os dados do Relatório de Produção Pesqueira Anual do Pará apontavam que a existência 275.000 pescadores cadastrados no Estado, sendo que pesca artesanal e industrial juntas são responsáveis pela captura e beneficiamento de 80 espécies de pescado, ao passo que a piscicultura paraense trabalha com 21 espécies (SEPAQ, 2014).

\section{PESCA E SUJEIÇÃO AO CAPITAL}

Apesar do Pará ser o estado com a mais relevante atuação da pesca industrial da Região Norte, a pesca artesanal é a responsável pela grande produção pesqueira do estado. Daí se entender que o capitalismo em formações periféricas se desenvolve sujeitando modos de produção com relações de produção não capitalistas, a um só tempo, e contraditoriamente, através de dois processos: a) a monopolização do território pelo capital monopolista; $b$ ) a territorialização do capital monopolista (OLIVEIRA, 1997). No primeiro processo as relações de produção são incorporadas à lógica capitalista sem o serem, ao passo que, no segundo, as relações em si já são capitalistas. Isto ajuda a entender como nos espaços agrários o campesinato não desaparece tendo sido reproduzido pelo e no próprio capitalismo (MARTINS, 2009), bem como nos espaços urbanos a chamada economia informal também não desaparece conforme avança o capitalismo, mas segue se reproduzindo no capitalismo (SANTOS, 2008).

Tal como demonstra Santos (2008), não há nenhuma irracionalidade na sobrevivência da economia informal, o qual nomeia de "circuito inferior". Trata-se de uma estruturaprocesso que responde aos próprios reclamos da reprodução da formação espacial sob a hegemonia capitalista. É a Preobrazensky que se deve a primeira sistematização dessas ideias, a partir do fio condutor deixado por Rosa Luxemburgo. Após analisar os três pontos centrais da teorização de Preobrazensky, Vergopoulos (1977, p. 105, grifos do autor), assevera:

Podemos dizer, enfim, que Preobrazensky deixou bem claro que a acumulação do capital não necessita da 'racionalização' da agricultura, mas da submissão da agricultura à racionalidade do setor industrial; o que pode, eventualmente, ser combinado com certo grau de 'irracionalidade' relativa da produção agrícola; conforme este ponto de vista, é, sobretudo, o pequeno agricultor que será compatível 
com um processo de pilhagem da agricultura, mais do que o grande proprietário fundiário.

Nestes temos, tanto o campesinato como a economia informal não somente não são aniquilados pelo capitalismo, mas, ao contrário, são reproduzidos por ele, na medida em que ambos são (em suas formas e funções atuais) o resultado da própria reprodução capitalista, como exterioridades a serem pilhadas, em uma acumulação por espoliação (HARVEY, 2005). A produção primeira, portanto, não é capitalista; o é apenas a sua reprodução. De acordo com Martins (2009, p. 80, grifos do autor):

As forças produtivas se desenvolvem mais depressa que as relações sociais; no capitalismo, a produção é social, mas a apropriação dos resultados é privada. Essa contradição fundamental anuncia o descompasso histórico entre o progresso material e o progresso social.

Em termos espaciais, portanto, reafirma-se, com base em Martins (2009), que nas formações capitalistas a produção do espaço é social, mas a apropriação do território é privada. No ajuste espacial rumo à periferia, a modernização do capital possui como sua forma correlata a precarização do trabalho, em virtude do capitalismo ser, em primeiro lugar, um modo de produção e extração de mais-valia mais que um modo de produção de mercadorias (VERGOPOULOS, 1977). Se o tema são as relações sociais (o território usado) e não os recursos (o território em si), seguindo a formulação de Santos (2005), o campesinato é uma relação não restrita às terras, mas aplicável às águas. Os pescadores constituem o campesinato das águas.

A apropriação do território pelas empresas provocou uma desterritorialização (enquanto "perda" do controle dos recursos do espaço) dos agentes que realizavam uma apropriação comum do território: os pescadores artesanais (SILVA, 2011). Estes perdem o acesso a determinadas espécies, principalmente a piramutaba por ser a mais lucrativa para a exportação, em face do aparato técnico das empresas, que eliminaram do alcance daqueles pescadores diversas espécies de peixes e crustáceos de forte interesse comercial. Estabelecido o novo padrão de regulação territorial, consolidado nos anos 1970, em pouco tempo os pescadores do litoral paraense já não tinham condições efetivas de se reproduzir dignamente com a pesca. Essa desterritorialização, contudo, implicou em uma reterritorialização que se deu através: $a$ ) da especialização da pesca de espécies que não interessam aos grandes atores; ou, $b$ ) da conversão dos pescadores em força de trabalho para os novos atores, as empresas de pesca industrial.

A reterritorialização é o modo de reprodução da pesca artesanal encontrado a após a expansão da pesca industrial, nesse caso uma territorialização precária (HAESBAERT, 
2009). Quando da especialização da pesca de espécies não rentáveis, o que está se dando é a produção de recursos para a reprodução da força de trabalho a ser explorada pelo capital, a qual comprará esses produtos com seus salários. Esta força de trabalho é local, do Nordeste Paraense, que reside ou trabalha nas principais praças pesqueiras, como a cidade da Vigia.

Quando da conversão dos pescadores em trabalhadores das empresas capitalistas, temos a territorialização do capital ipso facto. Trabalhando em moldes capitalistas, os assalariados das empresas pesqueiras ganham sob a forma de salários apenas o mínimo necessário à sua reprodução enquanto força de trabalho, às vezes menos que isso (VERGOPOULOS, 1977). O dinheiro é o meio pelo qual obtém o seu sustento. Ocorre que os alimentos que consomem são produzidos por outrem, e não se trata do pescado industrializado, uma vez que seu mercado consumidor não está na hinterlândia de Belém, no Nordeste Paraense.

Reafirma-se a necessidade orgânica da pesca artesanal (no circuito inferior) no próprio sistema hegemônico, enquanto reprodução dos meios de vida necessários à reprodução da força de trabalho. A pesca artesanal sobrevive, então, como auxiliar ou dependente do modo de produção capitalista, agregando, segundo Nogueira e Chagas (2011), os trabalhadores dispensados das empresas, fornecendo alimentos e, conforme os termos de Vergopoulos (1977), fornecendo também, através da troca desigual, mais-valia de transferência. Tem-se, assim, a dinâmica da pesca artesanal como um modo de produção dependente, hegemonizado, tal como o modo de produção camponês, teorizado e analisado por Amin (1977).

Na esfera do comércio envolvido no circuito espacial da produção da pesca artesanal há a materialização do circuito inferior da economia, o qual não está alijado da economia formal. É através desse circuito que os produtos "modernos" chegarão à maioria da população (SANTOS, 2008). Mas a troca é desigual, pois que estes produtos possuem mais trabalho acumulado. Entrementes, conforme vislumbrou-se nos números de produção, no que se refere à pesca artesanal no Pará, se está falando de um grande valor de mercado. Segundo a teoria, o mais provável é que o excedente extraído ficaria retido nas mãos dos agentes intermediários atravessadores - mas só será realizada no circuito superior (NOGUEIRA, CHAGAS, 2011). Não se trata, portanto, de um empecilho ao pleno funcionamento do capitalismo, mas um modo importante de extração do trabalho realizado (SANTOS, 2008), de mais-valia de transferência funcional ao modo de produção capitalista, que não é propriamente um modo de produção de mercadorias, mas um modo de produção de mais-valia.

Seria, então, o caso de afirmar que a produção do novo ordenamento territorial da pesca se dá simultaneamente - para utilizar os termos de Gottmann (1978), ressignificados por 
Santos (1995) - com a reterritorialização "enquanto recurso" para alguns e "enquanto abrigo" para outros. Contudo, todas regidas (ainda que não necessariamente determinadas em seu todo) pela mesma lógica da exploração do trabalho acumulado mediada pela técnica moderna (MOTA, 2016). Neste momento do processo-mundo, a mediação através da técnica moderna reproduz as condições para a reprodução ampliada do capital, seja no circuito superior ou inferior, este transferindo mais-valia àquele. Sob estes moldes, a reterritorialização da pesca artesanal deve ser vista como um momento do processo de reprodução ampliada do capital, ou melhor, um momento da totalização do capital (SOARES, 2016).

Assim, a reterritorialização elaborada é o novo modo de sobrevivência e circulação no espaço realizado pelos agentes não hegemônicos, ou seja, em novas relações sociedade/natureza. Em um primeiro momento como resposta imediata. Sua emancipação da estrutura hegemônica permanece potencial apenas. Isto porque, hipoteticamente, a natureza a ser reterritorializada estaria ressignificada por outro conjunto de técnicas, que implica em outro conjunto de normas. Destarte, a reprodução da atividade "tradicional" enquanto modo de produção dependente implica na apropriação de um novo conjunto de técnicas (reterritorialização), convertendo o artesanal em reprodução moderna da pobreza, porque se trata da reprodução da exploração e expropriação, onde fundamentalmente o espaço, produto da solidariedade orgânica entre os atores, segue apropriado (logo, territorializado) por um séquito.

\section{O ORDENAMENTO TERRITORIAL DA PESCA}

Historicamente na Amazônia a pesca artesanal tem tido dois padrões de ocupação: um padrão mais sedentário nos rios, ao passo que, no litoral, um padrão mais nômade (SILVA, 2011). Com a nova regulação estabelecida pelo ordenamento territorial hegemônico, as territorialidades tradicionais são entrechocadas com novas territorialidades. A cognoscibilidade da pesca tem sido transmitida e aplicada através da oralidade e da aprendizagem cotidiana, enquanto que, segundo Silva (2011), o papel da técnica definia a territorialidade (conjunto de práticas espaciais) dos pescadores, mas não definia os territórios (os "pesqueiros") de cada pescador ou grupo de pescadores. Conforme Silva (2011, p. 43): “os pesqueiros são os pontos de pesca onde há alguma forma de apropriação, regra, uso ou conflitos, sendo então territórios ocupados por determinados pescadores que conhecem naquele espaço delimitado uma apropriação". A gestão tradicional desses territórios se dá através da política dos acordos de pesca. 
Para Silva (2011, p. 44): “os territórios são reconhecidos segundo as atividades exercidas cotidianamente neste espaço, observando a estreita relação existente entre a utilização de tecnologias para o melhor uso dos recursos naturais, que interfere no modo de vida dos pescadores artesanais". Aqui, aproximando a noção geográfica clássica de "modo de vida" ao uso do território. No entanto, a nova lógica das empresas possui a própria técnica como política. E esta política resinifica a natureza, modificando os seus usos (modo de vida). "A cada período técnico corresponde uma mudança geral nas relações sociais" (SANTOS, 2009, p. 299). É assim que a pesca artesanal, como momento da totalização do capital vê sua reterritorialização afirmar o valor de troca produzido alhures, posto que, de acordo com Silva (2011, p. 48), cada vez mais, “(...) objetos e outros tipos de aparatos não dotados de simbologia tradicional para os pescadores passam a ser utilizados de forma mais frequente visto que este ambiente está aberto a novos atores e processos, mais ainda com o processo de globalização". Não há, portanto, uma desterritorialização estrita, mas um processo de reprodução das relações de produção mediado pelas forças em favor do capital.

A reterritorialização tanto a partir do assalariamento, como a partir da reprodução da pesca artesanal tem significado, em última instância, a reprodução ampliada do capital monopolista. Isso significa que os símbolos e a identidade que cimentavam a organização espacial anterior são reconfigurados a partir dos novos arranjos espaciais, para que produzam "novas iconografias" (GOTTMANN, 1978), novas identidades que coadunem com a apropriação desigual. A técnica não é mais ideologia, mas cotidiano. Porém, a contradição intrínseca da territorialização hegemônica, porque geradora de dois polos de acumulação inutilizados, um de capital e outro de trabalho (HARVEY, 2005), implica na reprodução de contraespaços. A questão que se impõe é entender o processo de concretização no Nordeste Paraense da nova regulação territorial regida pelas empresas capitalistas que necessita da sujeição da pesca artesanal ao capital.

Faz-se necessário entender quais as estratégias e as táticas (RAFFESTIN, 1993) utilizadas para viabilizar e reproduzir na escala local os planos do Estado maior, arranjo superestrutural em favor dos atores hegemônicos (MOREIRA, 1982). O uso da técnica moderna pressupõe a reprodução da estrutura classista na produção do espaço. Daí que os planos do Estado para a reprodução dos "modos de vida tradicionais" sejam, na realidade, planos para a incorporação plena da técnica (e da informação teleguiada) ao espaço. Novamente, aqui já não se trata meramente de ideologia, mas da realidade. A ideologia materializada nos objetos espaciais. De acordo com Santos (2009, p. 126): 
A realidade inclui a ideologia e a ideologia inclui a realidade. A ideologia, outrora considerada como falsa, portanto não-real, de fato não é algo estranho à realidade, nem é aparência apenas. Ela é mais do que aparência, porque é real.

A natureza já não possui sentido sem a técnica, porque não há modo de usufruir da primeira sem a última. Os programas para apoio e auxílio da pesca artesanal são programas técnicos, e o reclamo por parte dos pescadores artesanais, bem como da sociedade como um todo, são, por seu turno, reclamos por técnica. Com essa mudança nas relações sociais, a produção do cotidiano no espaço (e do lugar e da identidade), é, doravante, mediada pela técnica (MOTA, 2006). Ainda que se tenha a reprodução de relações de produção não capitalistas, os usos da técnica se convertem em usos banais do cotidiano, reproduzindo as relações de produção.

Assim, o próprio sentido da pesca artesanal é modificado, sendo convertido em fundamento do valor de troca, ainda que persista como uma produção aparentemente "sem patrões". Ainda que a produção se dê mediada em valor de uso. Daí se fazer necessário entender de que modo as comunidades que vivem a partir da pesca artesanal têm assimilado o novo conjunto técnico, como enxergam os seus territórios e os seus problemas, para se partir rumo a um novo ordenamento territorial que não seja sinônimo de disposição dos objetos em favor da reprodução ampliada do capital e da acumulação por espoliação

A viabilização destes planos altera as relações com a natureza, bem como a própria natureza local, modificando o lugar e o cotidiano dos indivíduos, normatizando a um só tempo os novos trabalhadores assalariados e os trabalhadores "autônomos". As territorialidades tradicionais são dissolvidas e têm-se, então, novas territorialidades incorporando novos elementos aos tradicionais. Alterado o modo de territorialização, a técnica é assimilada como necessidade de todos, e o discurso engendrado passa a ser um discurso "para todos", como se fosse, de fato, em favor de todos.

Molda-se, portanto, um espaço técnico-científico-informacional, onde a ciência e a informação atuam para legitimar as novas relações, em favor da hegemonia (SANTOS, 2008). Não se pode olvidar, contudo, a capacidade de contraposição aos planos hegemônicos por parte dos grupos sociais hegemonizados. O lugar nunca é inerte, ou um espaço vazio como queriam os militares, mas uma totalidade em si mesmo, na qual se moldaram elementos materiais e simbólicos que podem permitir a oposição ao ordenamento oficial, bem como a proposição e efetivação de contraespaços (MOREIRA, 2007). 


\section{A RETERRITORIALIZAÇÃO DA PESCA ARTESANAL}

Há três décadas a pesca industrial está consolidada no Nordeste Paraense (ALMEIDA et al, 2011), combinada com a reprodução da pesca artesanal, convertida em caudatária da pesca industrial no sentido da complementariedade de renda para as famílias e de peixes para a população (PENNER, 1984). A pesca artesanal segue reproduzida em favor do capital; e ainda assim, os pescadores resistem e (re)existem. Os pescadores da Vigia costumam se organizar em dois grupos: $a$ ) os "pescadores do chega e vira"; e, $b$ ) os "pescadores de fora" (NOGUEIRA, CHAGAS, 2011).

O primeiro grupo é composto pelos pescadores que apresentam menor aparelhamento tecnológico, e, por tal, realizam viagens curtas retornando diariamente para a Vigia. Deste modo, sua produção não ultrapassa quatro toneladas. Apesar do retorno diário à Vigia, sua área de atuação costuma incluir as águas oceânicas desde Curuçá até o nordeste da Ilha do Marajó, abrangendo o litoral de Soure e Salvaterra, além de frequentemente incluir as fozes dos rios Tocantins e Pará que desembocam na Baía do Marajó, um gigantesco canal fluvial a leste do arquipélago (NOGUEIRA, CHAGAS, 2011).

Já o segundo grupo, os "pescadores de fora", é composto por dois subgrupos: os “pescadores amazonistas", que descem as águas do Amazonas até o oceano, e os "pescadores nortistas", que fazem o percurso inverso do oceano ao Amazonas. Esses subgrupos mais que uma divisão, correspondem a momentos diferentes do mesmo grupo, que ora faz um percurso ora outro ao sabor da natureza das espécies e das marés (NOGUEIRA, CHAGAS, 2011).

Estes pescadores artesanais constituem uma grande comunidade pesqueira que se relaciona com várias comunidades, de modo harmônico ou não dependendo do caso, e que segue a lógica "nômade" apontada por Silva (2011). Em ambos os casos, contudo, há uma superexploração do trabalho. As espécies mais interessantes (a piramutaba e a dourada) são capturadas pelos barcos dos empresários (ALMEIDA et al, 2011), deixando aos pescadores artesanais a "opção" de prolongar sua jornada de trabalho ao limite corpóreo. Na Vigia, conforme Nogueira e Chagas (2011, p.71):

A dilapidação da força de trabalho dos "chega e vira" manifesta-se sob formas variadas e resulta do desgaste orgânico e mental que ultrapassa o que se costuma considerar normal, principalmente quando comparados às de muitas outras formas de trabalho, devido à extensa e continuada jornada de trabalho sob Sol, chuva, vento e umidade e a constância do trabalho sob essas condições. Soma-se a isso a expressiva jornada de trabalho dos "chega e vira" cuja extensão diária varia entre 12 e 18 horas, com momentos de grande intensidade e periculosidade, ressaltando, assim, a lógica e pertinência da 
expressão pela qual se designa "chega e vira". Mal chega à terra, para virar numa nova jornada de trabalho, partindo em seguida.

Não é diferente no caso dos "pescadores de fora" que executam viagens mais demoradas, mas que trabalham sempre com a urgência de preservar o gelo, mercadoria cara para os padrões da pesca artesanal. Além disso, os pescadores vigienses "amazonistas", ou seja, os que pescam nas fozes dos grandes rios têm a possibilidade de usar redes, e, portanto, pescar a noite. O seu trabalho é então desenvolvido ao longo das 24 horas do dia, variando entre cinco a dez horas de permanência da rede nas águas, num ciclo de dez a doze dias de pescaria até regressar ao litoral (NOGUEIRA, CHAGAS, 2011). De qualquer modo, esse excesso de trabalho acumulado, tanto dos "pescadores do chega e vira" quanto dos "pescadores de fora" é convertido em mais-valias de transferência no circuito superior da economia. Assim, de acordo com Nogueira e Chagas (2011, p. 75):

A pesca artesanal vigiense apresenta uma grande dependência de outros atores econômicos para poder subsidiá-la, em virtude, do pouco ou nenhum poder aquisitivo do pescador artesanal local. Neste sentido, mesmo na pesca artesanal de pequeno porte, onde já existem uma embarcação motorizada, há a presença do capital de empresas que fornecem materiais vendidos em seus estabelecimentos comerciais para o pequeno pescador que atua no município da Vigia. É uma espécie de crédito que o pescador recebe que é pago quando o mesmo retorna da pesca. Sendo que sobre o valor do material fornecido pelo comerciante ao pescador são acrescidos juros que chegam até $50 \%$ acima do valor real. Esse acréscimo é justificado pelo comerciante devido à demora apresentada pelo pescador para o pagamento do material "aviado".

Desta guisa, o pescador artesanal, a despeito de produzir uma territorialidade mais pautada na lógica territorial do abrigo, ou seja, na construção do território enquanto moradia e lar, fornece a riqueza a ser acumulada pelo circuito superior. Seu trabalho é utilizado na produção do espaço, que, entrementes, é territorializada segundo a lógica do valor de troca imposto por outrem. A técnica moderna como meio de relação com os recursos, ou seja, com a natureza, também já está dada e inserida no cotidiano como modo de vida. Mas isso não anula, de todo, o sentido da (re)existência. A despeito da funcionalização dada à pesca artesanal pelo capitalismo, persistem os pescadores comungando do mesmo problema: a pobreza cotidiana imposta por esta lógica perversa. A lentidão adrede engendrada pode ser o germe. "Ao contrário do que deseja acreditar a teoria atualmente hegemônica, quanto menos inserido o indivíduo (pobre, minoritário, migrante...), mais facilmente o choque da novidade o 
atinge e a descoberta de um saber lhe é mais fácil” (SANTOS, 2009, p. 330). Aí está o contraespaço em potência.

A visão do ordenamento dos recursos, segundo Diegues (2001), costumou ignorar a contribuição que as chamadas "populações tradicionais" ofereciam à manutenção do ecossistema. O modelo dominante de "conservação da natureza" está alicerçado no conhecimento ocidental dicotômico entre sociedade e natureza. Destarte, os grupos políticos filiados a este modelo de pensamento tendem a encarar as comunidades humanas como agentes destrutivos do meio ambiente e, suas organizações espaciais são responsabilizadas pela extinção de determinadas espécies, pelo desmatamento e conversão de parte da floresta em campos degradados, e pela contribuição à erosão do solo. Contudo, com a emergência da chamada "ecologia social", a partir dos anos 1980, há uma relativa virada em direção ao reconhecimento de que as sociedades tradicionais requerem, para reproduzir sua organização espacial intrínseca, uma alta diversidade de recursos naturais, e que, portanto, tais sociedades desenvolveram práticas culturais (materiais e simbólicas) que mantêm a biodiversidade (DIEGUES, 2001). A biodiversidade é fruto do manejo das sociedades tradicionais. Consequentemente, assegurar a sobrevivência dessas práticas é um excelente método para conservar a diversidade biológica.

$\mathrm{Na}$ Amazônia, existem alguns tipos de unidades de conservação em que a presença humana é garantida e orientada para a sustentabilidade ambiental, como as Reservas Extrativistas (RESEX), a quais, por definição elas são "espaços territoriais destinados à exploração autossustentável e conservação dos recursos naturais renováveis, por populações tradicionais" (IBAMA, 2004). O enfoque do desenvolvimento sustentável nesse tipo de unidade de conservação é totalmente possível e na Amazônia já é uma realidade. Além das RESEX existem também outros tipos de unidades de conservação que têm como objetivo básico preservar a natureza e assegurar condições e meios necessários para a reprodução e melhoria dos modos e da qualidade de vida e exploração dos recursos naturais das populações tradicionais, bem como valorizar, conservar e aperfeiçoar o conhecimento e as técnicas de manejo do ambiente, desenvolvido por essas sociedades.

Atualmente, a zona costeira paraense (Marajó e Nordeste Paraense) apresenta 22 Unidades de Conservação, sendo 20 de uso sustentável e duas de proteção integral, inseridas em 23 municípios da costa do estado. São 14 Unidades de Conservação da categoria Reserva Extrativista (RESEX), cinco são Áreas de Proteção Ambiental (APAs), uma Reserva de Desenvolvimento Sustentável (RDS), um Refúgio de Vida Silvestre (RVS) e um Parque 
Estadual (PES). Na Figura 2 é possível visualizar especificamente as RESEX e as APA da zona costeira paraense.

Figura 2: Mapa das RESEX e APA na Zona Costeira Paraense

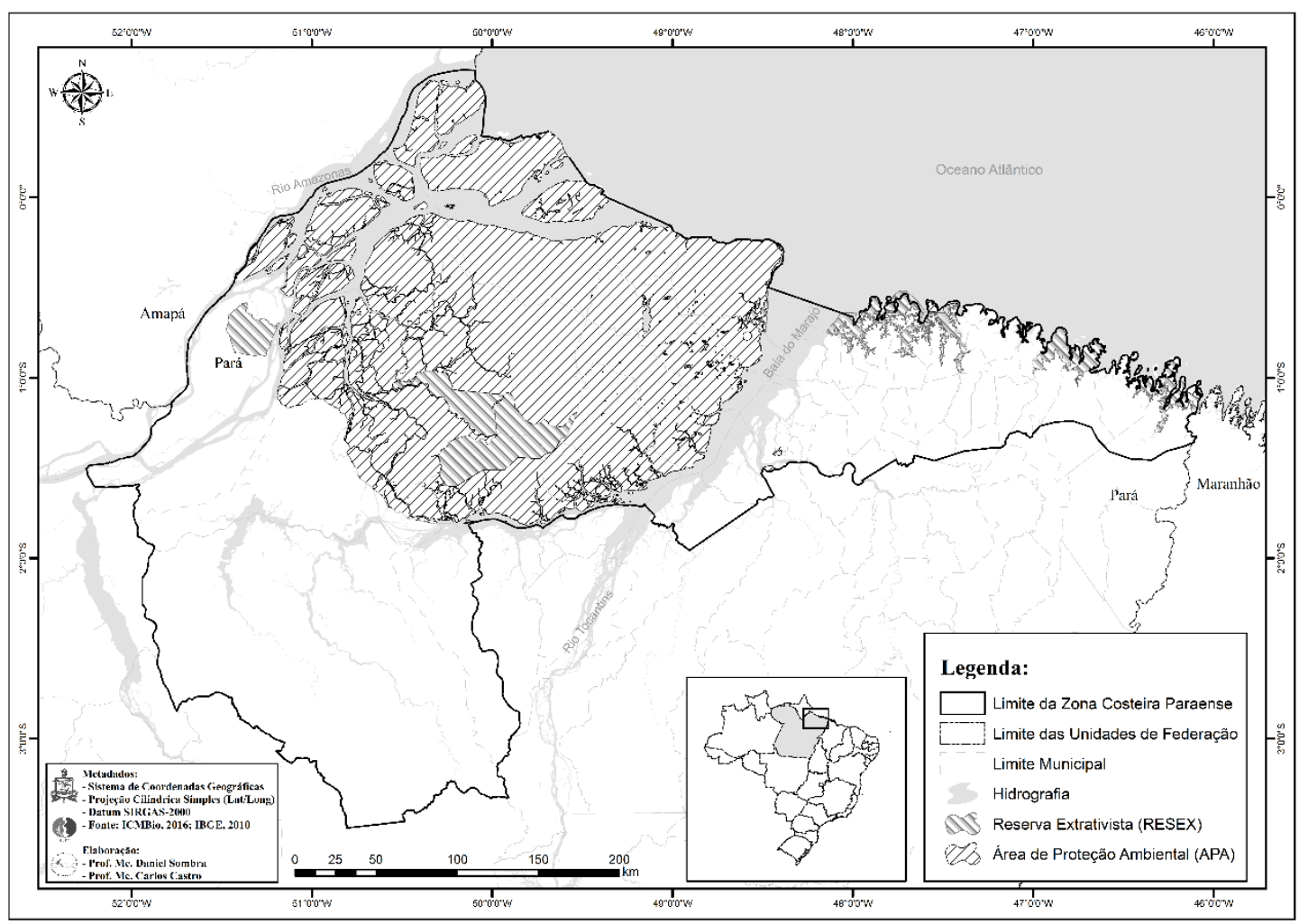

Fonte: ICMbio, IDEFLOR e IBGE, adaptado por SOMBRA e CASTRO (2017).

Segundo Diegues (2001), as relações de seres humanos com o ecossistema na Amazônia dependem das sociedades que ali vivem, já que existem diferenças marcantes entre elas. $\mathrm{O}$ impacto ao meio ambiente é claro, porém, os Povos Indígenas são, efetivamente, os que têm a melhor atuação na manutenção da floresta, embora seus padrões de comportamento variem à medida que se relacionam com uma economia maior. Além disso, os extrativistas tradicionais (seringueiros, quebradeiras de coco etc.) e os pequenos agricultores tradicionais (caboclos, ribeirinhos, pescadores) têm relativamente pouco impacto, comparado a outros grupos como fazendeiros, madeireiros, migrantes recentes e operações de agroindústrias.

Em verdade, qualquer mudança no meio ambiente, provocada pela produção em grande escala é sentida por estas sociedades através de mudanças climáticas e da degradação da capacidade produtiva dos sistemas naturais, como a degradação do solo, perda de recursos bióticos (populações de árvores e peixes comercialmente valiosos) e poluição da água. A maior bacia hidrográfica do planeta encontra-se na Amazônia. Sendo assim, a pesca é uma 
das atividades produtivas mais importantes, utilizando um de seus recursos mais abundante (o peixe), e abarcando um contingente humano considerável. No que se refere à força de trabalho ocupada no setor pesqueiro, é possível extrair os dados do Censo de 2000 (IBGE, 2000).

De acordo com o IBGE (2000), a Amazônia Legal possuía um contingente de 161.432 trabalhadores na pesca (ao passo que exclusivamente a Região Norte possuía 111.442 trabalhadores, representando $34 \%$ da força de trabalho). A Região Nordeste é que mais emprega na pesca: 152.548 trabalhadores (47\% da força de trabalho). As demais regiões Sudeste (com 33.198, representando $10 \%$ da força de trabalho), Sul (com 23.658, representando $7 \%$ da força de trabalho) e Centro-Oeste (com 5.580, representando $2 \%$ da força de trabalho) - têm menor participação no setor.

Na Amazônia Legal, os estados com maior ocupação de pessoal na pesca eram respectivamente: a) Pará, 69.829 trabalhadores (10,69\% da força de trabalho); $b$ ) Maranhão, 47.800 trabalhadores (7,2\% da força de trabalho); c) Amazonas, com 35.243 trabalhadores (5,4\% da força de trabalho); e, $d$ ) Amapá, com 2.335 trabalhadores $(0,36 \%$ da força de trabalho). Isso atesta a importância da pesca na Amazônia e por consequência uma atividade atrelada aos seus hábitos históricos e culturais. Os salários dos trabalhadores do setor pesqueiro só foram encontrados para o município de Belém. Para todas as outras capitais da Amazônia Legal, as estatísticas, do Centro Brasileiro de Ocupações, não mostraram qualquer dado para o trabalhador da pesca.

Tabela 1: Salários Médios de Admissão dos Trabalhadores da Pesca no Município de Belém Janeiro de 2003 à Janeiro de 2005 (Em reais)

\begin{tabular}{l|r|r|rr}
\hline Profissionais da Pesca & \multicolumn{1}{|c|}{$\mathbf{1}^{\circ}$ Emprego } & Reemprego & $\begin{array}{l}\text { Salário } \\
\text { Admissão }\end{array}$ & Médio \\
\hline $\begin{array}{l}\text { Trabalhador de } \\
\text { Preparação de Pescados } \\
\text { (limpeza) }\end{array}$ & 280,00 & 280,00 & 280,00 \\
\hline Pescador Profissional & & & 359,00 & 356,67 \\
\hline Pescador Industrial & 352,00 & 300,00 & 300,00 \\
\hline Técnico em Piscicultura & 300,00 & 600,00 & 600,00 \\
\hline
\end{tabular}

Fonte: MTE, 2005.

Como se vê pela tabela acima, os salários são baixos, mas ao nível do trabalhador médio. Em 2003 o salário mínimo oficial era de R \$240,00, enquanto que em 2005, o salário mínimo estava no valor de $\mathrm{R}$ \$300,00. Isto é condizente com o baixo nível de qualificação da própria mão-de-obra, para os critérios do modo de produção capitalista. Não obstante, os valores próximos à média do salário mínimo ajudam a compreender como os trabalhadores da 
atividade pesqueira, de fato, constituem um bloco de força de trabalho que ocupa posição similar aos trabalhadores assalariados do município de Belém.

Apesar dos baixos salários essa atividade é geradora de renda, e é para sociedades ribeirinhas o principal meio de sobrevivência, constituindo o peixe o principal produto de sua dietética. Conforme já citado, a pesca na Amazônia sempre foi uma atividade fundamental, atrelada aos hábitos culturais e à história da própria região. A partir dos anos 1930, ela deixa de ser uma atividade econômica apenas complementar para ser uma atividade especializada e intensiva. Para os dois principais insumos do setor pesqueiro - gelo e óleo diesel - algumas informações se tornam importantes.

No que se refere ao gelo ou fábricas de gelo nos municípios do Pará onde a pesca é mais intensiva e tem uma atividade comercial elevada, a então Secretaria Especial de Pesca e Aquicultura (SEAP) garantiu, em 2007 a construção de sete fábricas de gelo. Além disso, garantiu a construção de oito fábricas para toda a Região Norte. No que se refere ao óleo diesel, a média de consumo anual no ano de 2002 apenas para o estado do Pará foi de 367.063,25 litros, sendo a Companhia Ypiranga a maior fornecedora. O óleo diesel utilizado era subsidiado pelo governo federal em aproximadamente $25 \%$. A utilização desse óleo refere-se, para este mesmo ano, neste estado, a 234 embarcações entre barcos de pesca artesanal (5,55\%), pesca industrial (51,70\%) e armadores de pesca (42,73\%) (NPA, 2002). Importante ressaltar que a contagem direta de embarcações de pescadores artesanais ribeirinhos dessa imensa bacia demográfica é uma tarefa árdua.

\section{CONSIDERAÇÕES FINAIS}

Deste modo, a pesca artesanal na Região Norte detém o maior percentual $(80,6 \%)$ da produção total. Além disso, os outros estados da Amazônia Legal têm sua produção quase exclusivamente voltada para pesca artesanal e não para a industrial, com exceção da aquicultura continental e marinha que se conformam como atividades industriais. Em função disso, conclui-se que as sociedades tradicionais que ali residem detêm o conhecimento tácito e as formas de melhor utilizar o pescado. Assim, é certo identificar que são as sociedades tradicionais que residem na região quem conseguem a melhor utilização do recurso estando atreladas à efetiva conservação ambiental e, quem sabe, ao desenvolvimento sustentável. Segundo a Secretaria Executiva de Trabalho e Promoção Social (SETEPS, 2003), a pesca artesanal no estado do Pará era responsável por aproximadamente $60 \%$ do total de pescado produzido no Estado. Segundo dados do IBAMA (2004) esse percentual se eleva para 80,6\% 
do total pescado em toda região norte. E, ainda, de acordo com a SEPAQ (2014), mesmo no estado do Pará, o mais industrializado, no que tange à pesca, 96\% do total do pescado produzido é oriundo da pesca artesanal.

De acordo com SUDAM (2006), a produção pesqueira paraense é voltada para comercialização $(89,1 \%)$ e apenas uma pequena parte $(7,2 \%)$ é voltada para o consumo próprio. $\mathrm{O}$ restante da produção $(3,7 \%)$ é destinado à doação para parentes e amigos. Além disso, a SETEPS (2003) fez um levantamento junto a 65 Colônias de Pescadores em todo o estado do Pará, o qual atestou que a maioria dos entrevistados (amostra de 1215 pescadores) vê a Colônia como um órgão representativo da classe, característica importante para o exercício da profissão, para o aumento da comercialização e para os benefícios sociais que lhes são devidos. Deste modo, as Colônias teriam concretizado o objetivo da Marinha ao criálas: tornar-se um órgão efetivo de construção da cidadania para fins de controle efetivo do território por parte das forças armadas através do seu uso pelos próprios civis, conforme explica Resende (2014). Tal como no início do século passado, quando os pescadores artesanais foram enxergados como atores estratégicos para a soberania nacional e o ordenamento territorial (RESENDE, 2014), processo similar ocorre no início deste século.

No que se refere às micro e pequenas empresas ligadas ao setor de pesca na Amazônia Legal, de acordo com a Sebrae (2002), pode-se observar que a quantidade mais expressiva de empresas se encontra no Amazonas e Pará, sendo que o estado do Pará apresentava uma quantidade consideravelmente maior. O estado do Amazonas apresenta uma quantidade de empresas mais pulverizada. O Maranhão também apresentava micro e pequenas empresas em boa parte do estado, mas, à semelhança do Amazonas, em uma quantidade menor. Em suma, segundo o Sebrae (2002), naquele ano, o Pará possuía 98 micro/pequenas empresas pesqueiras, ao passo que o Maranhão possuía 28 e o Amazonas 24 micro/pequenas empresas pesqueiras. E, ainda, Rondônia apresentava oito microempresas pesqueiras, ao passo que Amapá e Acre apresentavam quatro microempresas cada um. Os estados de Roraima e Tocantins apresentavam uma empresa registrada cada um.

As micro/pequenas empresas amazonenses localizavam-se nos seguintes municípios: $a$ ) 11 em Manaus; $b) 3$ em Tefé; $c$ ) 2 em Manacapuru; d) 2 em Itacoatiara; $e$ ) 1 em Tabatinga; $f$ ) 1 em Rio Preto da Erva; $g$ ) 1 em Nhamundá; $h$ ) 1 em Lábra; $i) 1$ em Coari; e, j) 1 em Cadajás. Ao passo em que as micro/pequenas empresas maranhenses localizavam-se nos seguintes \begin{tabular}{l} 
municípios: a) 6 em São Luís; b) 3 em Tutóia; $c$ ) 2 em Rosário; d) 2 em São José de Ribamar; \\
\hline Sombra et al, 2018
\end{tabular} 
e) 2 em Barreirinhas; f) 2 em Cururupu; g) 1 em Guimarães; h) 1 em Imperatriz; i) 1 em Codó; j) 1 em Carutapera; $k$ ) 1 em Água Doce do Maranhão; $l$ ) 1 em Cândido Mendes; m) 1 em Itapecuru Mirim; n) 1 em Paço do Limiar; o) 1 em Pedreiras; p) 1 em Presidente Juscelino; e, q) 1 em Trizidela do Vale. Já no estado do Pará, em 2002, de acordo com o Sebrae (2002), as empresas localizavam-se nos seguintes municípios: $a$ ) 60 em Belém; $b$ ) 4 na Vigia; c) 4 em Marapanim; d) 3 em Santarém; e) 3 em Altamira; f) 3 em Curuçá; $g$ ) 3 em São Francisco do Pará; $h$ ) 2 em Santa Isabel do Pará; i) 2 em Santana do Araguaia; j) 2 em Vitória do Xingu; k) 1 em Santo Antônio do Tauá; $l$ ) 1 em Maracanã; m) 1 em Salinópolis; $n$ ) 1 em Limoeiro do Ajuru; $o$ ) 1 em Mocajuba; $p$ ) 1 em Abaetetuba; q) 1 em Moju; $r$ ) 1 em Marabá; $s) 1$ em Itaituba; $t$ ) 1 em São Félix do Xingu; $u$ ) 1 em Santarém Novo; e, v) 1 em Faro.

É possível afirmar, de acordo com os dados elencados, que: a) a pesca artesanal encontrou o seu lugar de reprodução em meio à ampliação dos espaços produtivos do capitalismo; $b$ ) os pescadores artesanais em comparação com a totalidade a qual lhes submerge comportam-se como sujeitos sociais camponeses, por suas relações sociais entre si e com o capital; $c$ ) a pesca artesanal conclui um momento de sujeição ao capital, e, destarte, não é possível conjecturar previsões de durabilidade eterna da categoria, sendo ela funcional neste período do processo de totalização do capital. Outrossim, o processo de sujeição da pesca ao capital é antigo, e mesmo fundante da atividade na colonização da Amazônia, e, mesmo na pesca artesanal, ainda que prevaleçam relações não assalariadas, há clara extração de excedente dos parceiros (pescadores despossuídos) em relação aos proprietários.

Por outro lado, a institucionalização das micro e pequenas empresas, assim como das Reservas Extrativistas resultou em novas oportunidades para os pequenos produtores de se livrarem da mediação dos tradicionais atravessadores que detinham o controle da esfera da circulação da produção. Ainda que, em última instância, esse processo implique na subsunção real do trabalho ao capital, agora projetada ao nível do espaço geográfico desde a escala do Estado nacional sobre as relações de produção nas arenas locais, isso também significa oportunidades concretas de reterritorialização da pesca artesanal não somente como existência, mas como projetos alternativos de contraespaços.

\section{REFERÊNCIAS BIBLIOGRÁFICAS}

ALMEIDA, O.; RIVERO, S.; ANDROCZEVECZ, S. "Espécies exploradas pela indústria pesqueira na Amazônia". In: SILVA, J. M. P.; SILVA, C. N. (org.). Pesca e territorialidades: contribuições para a análise espacial da atividade pesqueira. Belém: GAPTA/UFPA, 2011, pp. 27-38.

AMIN, S. O desenvolvimento desigual: ensaio sobre as formações sociais do capitalismo periférico. Trad.: F. R. C. Fernandes. Rio de Janeiro: Forense Universitária, 1976.

$\begin{array}{lll}\text { Sombra et al, } 2018 & \text { ISSN 0104-5490 }\end{array}$


AMIN, S. "O capitalismo e a renda fundiária". In: AMIN, S.; VERGOPOULOS, K. A questão agrária e o capitalismo. $2^{a}$ Ed. Trad.: B. Resende. Rio de Janeiro: Paz e Terra, 1977, pp. 9-40.

ANDRADE, M. C. Paisagens e problemas do Brasil: aspectos da vida rural brasileira frente à industrialização e ao crescimento econômico. $3^{\text {a }}$ Ed. Rio de Janeiro: Brasiliense, 1970.

CÓRDOBA, D.; SELFA, T.; ABRAMS, J. B; SOMBRA, D. "Family farming, agribusiness and the state: building consent around oil palm expansion in post-neoliberal Brazil". In: Journal of Rural Studies, Amsterdam, v. 57, pp. 147-156, jan. 2018.

COSTA, F. A.; INEHETVIN, T. Agropecuária na economia de várzea do Rio Solimões/Amazonas: diagnóstico e perspectiva. Belém: IBAMA, 2005.

DIEGUES, A. C. O mito moderno da natureza intocada. São Paulo: Hucitec, 2001.

FURTADO, L. G. Pesca artesanal: um delineamento de sua história. In: Boletim do Museu Paraense Emilio Goeldi, Belém (PA), n. 79, pp. 1-50, abr. 1981.

FURTADO, L. G. Redeiros e curralistas: pescadores do litoral do Pará. Belém: MPEG, 1987.

GONÇALVES, C. W. P. Amazônia, Amazônias. São Paulo: Contexto, 2001.

GOTTMANN, J. The significance of territory. Charlottesville: The University Press of Virgina, 1978.

HAESBAERT, R. O mito da desterritorialização: do "fim dos territórios" à multiterritorialidade. $4^{\text {a }}$ Ed. Rio de Janeiro: Bertrand Brasil, 2009.

HARVEY, D. A produção capitalista do espaço. Trad.: C. Szlak. São Paulo: Annablume, 2005.

IANNI, O. A luta pela terra: história social da terra e da luta pela terra numa área da Amazônia. $2^{\text {a }}$ Ed. Petrópolis: Vozes, 1979.

IBAMA, Instituto Brasileiro do Meio Ambiente e dos Recursos Naturais Renováveis. Estatística da pesca 2003: Brasil, grandes regiões e unidades da federação. Brasília: IBAMA, 2004.

IBGE, Instituto Brasileiro de Geografia e Estatística. Censo demográfico de 2000. Disponível em: < http://www.ibge.gov.br/home/estatistica/populacao/censo2000/>.

KLAUTAU, A. G. C. M. A pesca industrial da piramutaba na foz do Rio Amazonas. Dissertação (Mestrado em Aquicultura e Recursos Aquáticos Tropicais). Universidade Federal Rural da Amazônia, Belém, 2012.

LOBATO, M. M.; SOARES, D. A. S. "Fronteira na geografia: proposições para uma reflexão". In: Boletim Amazônico de Geografia, Belém (PA), v. 2, n. 3, pp. 175-193, jan./jun. 2015.

LOUREIRO, V. R. Os parceiros do mar: natureza e conflito social na pesca da Amazônia. Belém: MPEG, 1985.

LOUREIRO, V. R. A miséria da ascensão social: capitalismo e pequena produção na Amazônia. São Paulo: Marco Zero, 1987.

LOUREIRO, V. R. Amazônia: Estado, homem e natureza. $2^{a}$ Ed. Belém: CEJUP, 2004.

MARTINS, J. S. Fronteira: a degradação do outro nos confins do humano. $3^{\text {a }}$ Ed. São Paulo: Contexto, 2009.

MTE. Ministério do Trabalho e Emprego. Relação Anual de Informações Sociais: 20032005. Brasília: MTE, 2005.

MONTEIRO, M. A.; COELHO, M. C. N. "As políticas espaciais e reconfigurações territoriais na Amazônia". In: Novos Cadernos NAEA, Belém (PA), v.7, n.1, pp. 91-122, jun. 2004.

MOREIRA, R. "A Geografia serve para desvendar máscaras sociais”. In: MOREIRA, R. Geografia, teoria e crítica. Petrópolis: Vozes, 1982 
MOREIRA, R. "O espaço e o contra-espaço". In: SANTOS, M. et al. Território, territórios: ensaios sobre ordenamento territorial. $3^{\text {a }}$ Ed. Rio de Janeiro: Lamparina, 2007, pp. 72-108.

MOTA, G. S. Contribuições para uma teoria geográfica do lugar. 152f. Dissertação (Mestrado em Geografia), Universidade Federal do Pará, Belém, 2006.

MOTA, G. S. O Prometeu traído: espaço, técnica e controle no capitalismo monopolista e tecnológico. 248f. Tese (Doutorado em Geografia), Universidade Federal Fluminense, Niterói, 2016.

NAHUM, J. S.; MALCHER, A. T. C. "Dinâmicas territoriais no espaço agrário da Amazônia: a dendeicultura na microrregião de Tomé-Açu”. In: Confins - Revista Franco-Brasileira de Geografia, São Paulo (SP), n. 16, pp. 1-17, 2012.

NOGUEIRA, O. M. O.; CHAGAS, C. A. N. "A atividade pesqueira artesanal: organização da produção e dinâmica da circulação do pescado no município de Vigia-PA". In: SILVA, J. M. P.; SILVA, C. N. (org.). Pesca e territorialidades: contribuições para a análise espacial da atividade pesqueira. Belém: GAPTA/UFPA, 2011, pp. 67-77.

NPA, Núcleo de Pesca e Aquicultura. Delegacia Federal de Agricultura do Pará. Levantamento Anual. Belém, 2002.

OLIVEIRA, A. U. Amazônia: monopólio, expropriação e conflitos. Campinas: Papirus, 1987.

OLIVEIRA, A. U. A agricultura camponesa no Brasil. São Paulo: Contexto, 1997.

OLIVEIRA, F. “A crise da Federação: da oligarquia à globalização". In: AFFONSO, R. B.;

SILVA, P. L. B. A Federação em perspectiva. São Paulo: FUNDAP, 1996.

PENNER, M. E. S. A dialética da atividade pesqueira no Nordeste Amazônico. Belém: EDUFPA, 1984.

RAFFESTIN, C. Por uma geografia do poder. Trad.: M. C. França. São Paulo: Ática, 1993. RESENDE, A. T. "A origem da institucionalidade da pesca artesanal". In: SILVA, C. A. (org.). Pesca artesanal e produção do espaço: desafios para a reflexão geográfica. Rio de Janeiro: Consequência, 2014, pp. 69-86.

SANTOS, M. Por uma economia política da cidade: o caso de São Paulo. São Paulo: Hucitec, 1994.

SANTOS, M. "Da política dos estados à política das empresas". In: Cadernos da Escola do Legislativo de Minas Gerais, Belo Horizonte (MG), n. 6, pp. 9-23, 1995.

SANTOS, M. "O retorno do território". In: Observatório Social de América Latina, Buenos Aires, v. 6, n. 16, pp. 251-261, junho de 2005.

SANTOS, M. O espaço dividido: os dois circuitos espaciais da economia urbana nos países subdesenvolvidos. $2^{\mathrm{a}}$ Ed. São Paulo: EDUSP, 2008.

SANTOS, M. A natureza do espaço: técnica e tempo, razão e emoção. $4^{a}$ Ed. São Paulo: EDUSP, 2009.

SETEPS, Secretaria Executiva de Trabalho e Promoção Social do Estado do Pará. A Pesca Artesanal no Estado do Pará: perfil socioeconômico e organizacional dos pescadores filiados às colônias. Belém: SETEPS, 2003.

SEPAQ, Secretaria de Pesca e Aquicultura do Estado do Pará. Sobre a pesca industrial. 23 de novembro de 2014. Disponível em: < http://sepaq.pa.gov.br/?q=node/21>. Acesso em 12 de fevereiro de 2015.

SILVA, C. N. "Percepções ambientais-territoriais de pescadores artesanais do estuário amazônico". In: SILVA, J. M. P.; SILVA, C. N. (org.). Pesca e territorialidades: contribuições para a análise espacial da atividade pesqueira. Belém: GAPTA/UFPA, 2011, pp. 39-51. 
SOARES, D. A. S. Subsunção do trabalho ao capital na atividade pesqueira paraense: elites locais e contraespaços. 327f. Dissertação (Mestrado em Geografia), Universidade Federal Fluminense, Niterói, 2016.

SOARES, D. A. S.; LEITE, A. S.; LOBATO, M. M. "Estado e capital: subsídios para a compreensão analítica do protagonismo do Estado brasileiro no rearranjo espacial da América do Sul”. In: Revista Geoamazônia, Belém (PA), v. 4, n. 7, pp. 47-77, jan./jun. 2016.

SUDAM, Superintendência de Desenvolvimento da Amazônia. Plano de Desenvolvimento sustentável da Amazônia Legal: Estudos diagnósticos setoriais - PDSA 2005-2008. Belém: ADA, 2006.

VELHO, O. G. Capitalismo autoritário e campesinato: um estudo comparativo a partir da fronteira em movimento. São Paulo/Rio de Janeiro: Difel, 1976.

VERGOPOULOS, K. "Capitalismo disforme: o caso da agricultura no capitalismo". In: AMIN, S.; VERGOPOULOS, K. A questão agrária e o capitalismo. $2^{\text {a }}$ Ed. Trad.: B. Fernandes. Rio de Janeiro: Paz e Terra, 1977, pp. 41-17. 